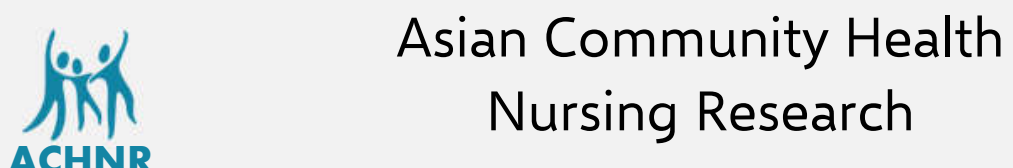

Asian Comm. Health Nurs. Res. 2019, 1(1), 34-38

\title{
Quality of Life School-Age Children with Attention Deficit Hyperactivity Disorder (Adhd) in Slb C Bandung
}

\author{
Adelse Prima Muya*, Desy Indra Yani and Helwiyah Ropi \\ Community Health Nursing Departement, Faculty of Nursing Universitas Padjadjaran, Jl. Raya Bandung- \\ Sumedang KM 21, 45363, West Java, Indonesia; desy.indra.yani@unpad.ac.id; helwiyah_fik@yahoo.co.id \\ *Correspondence: adelse@unpad.ac.id; Tel.: +6285375540558
}

Type of the Paper (Article)

Received: January 21, 2019; Accepted: January 31, 2019; Published: February 3, 2019 https://doi.org/10.29253/achnr.2019.13413

\begin{abstract}
Attention Deficit Hyperactivity Disorder (ADHD) is a behavioral characterized by attention deficit disorder, impulsive behavior, accompanied by excessive activity that is not in accordance with its age in childhood. ADHD can impact on decreasing the Quality of Life (QoL) of children. The study aimed to describe the QoL of ADHD children in SLB C Bandung. The research using descriptive study. The subjects were 63 families with ADHD children with an age range of 8-12 years who attended school in 5 types of SLB C in Bandung. Sampling used total sampling technique with inventory questionnaires including a child QoL questionnaire (Peds QL). Data were analyzed using descriptive analyze. The results showed that more than half of the QoL of ADHD children was classified as poor. The QoL of children with ADHD is very important because there are various aspects in their lives, both in terms of health, emotional, social, and school activities. This study explains QoL of ADHD children starting from physical, logistical, social and school functions. From this explanation, it is expected that in the part of QoL for ADHD children to be repaired, also which parts can be repaired and the care and attention needed to be improved.
\end{abstract}

Keywords: Attention Deficit Hyperactivity Disorder (ADHD); School-Age Children; Quality of Life

\section{Introduction}

Common problems that often hinder the development of school-age children are Attention Deficit Hyperactivity Disorder (ADHD) or Attention Deficit / Hyperactivity Disorder (ADHD). ADHD is a behavioral disorder characterized by inattentiveness, impulsivity, and can be accompanied by excessive activity (overactivity/hyperactivity) that is not in accordance with age in childhood (American Psychiatric Association /APA, 2000).

The case of ADHD is increasingly common in the community, where the incidence is increasing especially in school-age children. The prevalence of ADHD in school-aged children worldwide is around $3 \%-10 \%$, although prevalence rates vary substantially (Polanczyk, de Lima, Horta, Biederman, \& Rohde, 2007). The prevalence of ADHD in East Asian countries, shows a similar prevalence between West and non-West, which is around 8.1\% to 8.6\% (Gau, Chong, Chen, \& Cheng, 2005; Takahashi, Miyawaki, Suzuki, Mamoto, Matsushima, Tsuji , \& Kiriike, 2007). In Indonesia, the incidence rate is still not certain, even though this disorder appears to be quite a lot and is often found in preschoolers and school-aged children 
(Judarwanto, 2007). However, in a study by Wihartono (2007), the prevalence of ADHD in West Java Province, especially in the city of Bandung for elementary school students and special needs schools was found at $2.70 \%$.

The impact of the three combinations of ADHD symptoms including symptoms of hyperactivity, intensity, and impulsivity which can lead to abnormal development of the child which makes it difficult for children with ADHD to perform at school. Hyperactive behavior makes ADHD children have difficulty when in social institutions (Vaughan, Roberts \& Needelman, 2009). Many of the ADHD children have difficulties in the school environment, often having problems in disciplinary forms or academic difficulties (Weyandt \& DuPaul, 2006).

This condition certainly causes suffering and obstacles for children in carrying out their daily functions. Various other disorders that can occur in ADHD children such as lack of confidence in children, disorders of interacting with peers, family and also disrupting the child's ability to learn and overall will reduce the quality of children's lives (Escobar, Soutullo \& Hervas, 2005 ; Nijmeijer, Minderaa, \& Buitelaar, 2008; Varni \& Burwinkle, 2006; Strine, Lesesne, \& Okoro, 2006).

The Quality of Life (QoL) of children with ADHD is inseparable from several factors that influence it. According to Jeanne, Landgraf, Rich, \& Rappaport (2002) the QoL factors for ADHD children can be seen from the impact caused or AIM (ADHD impact module) including children's health status, frequency of "successful" experiences of children with parents at home, parent assessment (child health, child discipline, parenting for children, and child behavior), the time of diagnosis of the child, how long the child gets treatment, and the role of the family in supporting ADHD children. Other factors that affect the QoL of children with ADHD include demographic factors, family support, clinical, physical, emotional, family and social anxiety (Riley, 2006; Wehmeier, Schacht, \& Barkley, 2010; Sánchez, Cortés, Carlos, Moreno \& Poblano 2012 ; Theule, 2010).

adverse conditions for both ADHD children and families, this certainly requires the support and participation of health workers, one of which is school health-based community nursing. School healthbased community nursing not only pays attention to the QoL of schoolchildren but pays attention to all aspects, both school, family, and society as a whole and organized. According to the Centers for Disease Control and Prevention (2011); Murray, Low, Hollis, Cross, \& Davis (2007), community nursing responsibilities for school health include; health education, physical health education, health services, nutrition services, counseling, psychological and social services, healthy school environment services, health promotion of teacher staff in schools, and community and family involvement.

However, the existence of community health-based community nurses is still not active in Indonesia, especially in Bandung. Community nurses fully still do not pay attention to school health, especially the health of schools with special needs. Community nurses still tend to provide comprehensive primary care services to various age groups.

Starting from the statements above, in Indonesia, no research has been conducted on the QoL of children with ADHD. Although research on the QoL of ADHD children has been carried out in America and Europe, similar research is also important in Indonesia because it sees the demographic factors of these countries very much different from the demographic conditions in Indonesia. Therefore, the authors are interested in looking at an overview of QoL of ADHD children in SLB C Bandung.

\section{Methods}

This research was a descriptive study that aims to described of QoL of ADHD children. The research design used was a cross-sectional study. The sample in this study were families that had school-age children who had ADHD with inclusion criteria including: 1) school-age children aged 8-12 who have a diagnosis of ADHD by a psychiatrist; 3) attending education at SLB C in Bandung; 4) living at home with biological parents; 5) parents are willing to follow the research process; 6) ADHD children owned by families did not experience other physical disabilities such as blind, mute, paralyzed and so on. Sampling used a total sampling system with a total sample size of the population of 63 respondents spread over 5 SLB C in Bandung.

QoL of children with ADHD was measured using the Pediatric QoL Inventory (PedsQL) Generic Core version 4.0. The questionnaire is composed of 23 statements consisting of: 1) Physical function 8 statements; 2) Emotional functions 5 statements; 3) Social functions 5 statements; and 4) School functions 5 statements. This questionnaire consists of answer choices using a Likert scale (never, 
sometimes, often and always). The answer was never worth 1 , sometimes worth 2 , often worth 3 and always worth 4 for positive statements while negative questions have the opposite value. All answers will be added to the total score. The highest score was 92, and the lowest score is 23. The QoL of ADHD children was stated to be good if the total score of QoL of ADHD children had a range of values of 47-92 and is declared poor with a range of values 23-46.

This questionnaire had been tested for validity and reliability testing with Alpha Cronbach's for (0.90). The questionnaire used is an inventory questionnaire in English, so the translation had been done first into Indonesian and the translation was back into English (back translation) which was done and has been examined by two lecturers who are competent in their field. From the results of the back translation, there was no difference in meaning between the English-Indonesian and Indonesian-English transitions, so this questionnaire could be used. This study used univariate analysis which aims to explain or describe each research variable, in this case, was the QoL of ADHD children.

\section{Results}

The results of the study below illustrated quality of life of ADHD children seen from the score criteria.

Tabel 1. Quality of Life of ADHD Children Based on Score Criteria in SLB Type C Bandung 2015 (N=63).

\begin{tabular}{lcccc}
\hline \multicolumn{1}{c}{ Variable } & Score Criteria & Min-Max & Mean & SD \\
\hline $\begin{array}{l}\text { Quaity of Life ADHD } \\
\text { Children : }\end{array}$ & $23-92$ & $35-64$ & 44.6 & 9.3 \\
$\quad$ Physical function & $8-32$ & $8-29$ & 19.4 & 5.4 \\
Emotional function & $5-20$ & $5-17$ & 9.6 & 4 \\
Social function & $5-20$ & $5-17$ & 8.6 & 3 \\
School function & $5-20$ & $5-16$ & 9.8 & 3 \\
\hline
\end{tabular}

Based on table 1 above it is known that the overall QoL is 44.6 with an average physical function of 19.4 emotional functions 9.6 social functions 8.6 and school functions $9.8(\mathrm{~N}=63)$.

The results of the study below illustrated quality of life of ADHD children seen from the variable categorization.

Tabel 2. Description of Quality of Life ADHD Children Based on Classification in SLB Type C Bandung $2015(\mathrm{~N}=63)$.

\begin{tabular}{lcc}
\hline Variable & Frecuency (f) & Percentase (\%) \\
\hline Quality of Life ADHD & & \\
Children: & 21 & 33.3 \\
Good & 42 & 66.7 \\
Poor & as poor $(\mathrm{N}=63)$.
\end{tabular}

\section{Discussion}

The QoL is an important aspect of health which describes the ability of individuals as a whole both physically, emotionally, socially and environmentally (school). This study looked at the QoL of ADHD children in terms of children's ability to do things in various aspects including physical, emotional, social and school functions. QoL was assessed using a questionnaire filled in by parents of children who all used negative statements regarding physical, emotional, social and school functions. If the child gets a higher score with a maximum limit of 92 then the QoL of the child is said to be good, whereas if the family gets the lower value nearing the minimum limit of 23 points, the QoL of the child is declared to be poor. 
Based on the results of the study, the QoL of ADHD children more than half (66.7\%) was categorized as poor and the rest (34.3\%) were categorized as good. The average results of total QoL scores obtained by children are 44.6 with min-max values (35-64). The results of the total score of QoL include several dimensions including physical function with an average value of 19.4. Emotional function has an average value of 9.6. Then social functions with an average value of 8.6 and school function with an average score of 9.8. The overall dimensions of the QoL of ADHD children with social function dimensions have the lowest average, meaning that the QoL of ADHD children is still lacking in terms of social function.

The results of this study are similar to those of Jafari, Ghanizadeh, Akhondzadeh, \& Mohammadi (2011), measuring the QoL of children with ADHD can use Peds QL. The results of this study obtained a reliability analysis value of 0.85 and showed that the QoL of children with ADHD was lower than children who had cancer. Seid, Varni, Segall, \& Kurtin (2004) ADHD children have a low QoL and need immediate intervention. Research by Sánchez, Cortés, Carlos, Moreno \& Poblano (2012) children's emotional factors tend to cause the quality of children to decline.

According to Ridley \& Young (2002) health-related QoL / HRQOL describes the views of individuals or families about the health level of these individuals after experiencing illness and getting a form of management. Health-related QoL describes a multidimensional healthy and functional component such as physical, emotional, mental, social and behaviors perceived by patients or other people around the patient (parent or caregiver).

The QoL of ADHD children is depicted with feelings of happiness and the good condition possessed by ADHD children including physical, emotional, family, social, and achievement in school as well as a decrease in childhood illness (Loonen, Derkx and Otley, 2001; Richardson Griffiths, Miller, \& Thomas, 2001; and Ware \& Dewey, 2000). The QoL of children with ADHD is very important to know by a community nurse. King \& Hinds (2011) stated that the perspective of QoL is very relevant to the realm of nursing. King \& Hinds (2011) QoL refers to how to make life more valuable, this connotation with aspects of caring in the realm of nursing, because nursing not only pay attention to survival and decrease client pain, but more to aspects overall to the client including a meaningful life (QoL).

Nursing is the practice of "caring" where nurses help maintain and promote the health of clients, including improvement of functions. Through data on the QoL of clients, nurses will be more able to provide assistance to clients in terms of providing care, improving health and providing motivation in dealing with the problems they face in order to increase their sense of comfort (happiness) in dealing with their illness.

Normally children with health problems, especially mental health and behavior, will tend to experience a decrease in their QoL. Biologically the child has a disruption in the cerebral system, this is what really triggers the behavior of the child so that the child is difficult to control his behavior. As a result, children find it difficult to socialize, achieve achievements and even experience emotional disturbances.

\section{Conclusions}

The QoL of children with ADHD is very important because there are various aspects in their lives, both in terms of health, emotional, social, and school activities. This study explains the QoL of ADHD children starting from physical, logistical, social and school functions. From this explanation, it is expected that in the part of the QoL for ADHD children to be repaired, also which parts can be repaired and the care and attention needed to be improved.

\section{References}

American Psychiatric Association. (2000). Diagnostic and Statistical Manual of Mental Disorders. 4th, Text Revised. Washington, DC: American Psychiatric Press, Inc.

Centers for Disease Control and Prevention (CDC. (2011). School health guidelines to promote healthy eating and physical activity. MMWR. Recommendations and reports: Morbidity and mortality weekly report. Recommendations and reports/Centers for Disease Control, 60(RR-5), 1.

Escobar, Soutullo C.A,Hervas A. (2005). Worse QoL for children with newly diagnosed attention-deficit/hyperactivity disorder, compared with asthmatic and healthy children. Pediatrics. 13, 234-250

Jafari, P., Ghanizadeh, A., Akhondzadeh, S., \& Mohammadi, M. R. (2011). Health-related QoL of iranian children with attention deficit/hyperactivity disorder. QoL Research, 20(1), 31-6. doi:http://dx.doi.org/10.1007/s11136-010-9722-5. 
Jeanne, Landgraf, Rich, \& Rappaport. (2002). Measuring Quality of Life in Children With Attentiondeficit/Hyperactivity Disorder and Their Families: Development and Evaluation of a New Tool. Arch Pediatr Adolesc Med. 156(4):384-391. doi:10.1001/archpedi.156.4.384.

Gau, S. S., Chong, M. Y., Chen, T. H., \& Cheng, A. T. (2005). A 3-year panel study of mental disorders among adolescents in Taiwan. American Journal of Psychiatry, 162, 1344-1350.

Judarwanto, W. (2007). Penatalaksanaan attention deficit hyperactive disorders pada anak. Tesis. Universitas Gajah Mada.

Murray, N. G., Low, B. J., Hollis, C., Cross, A. W., \& Davis, S. M. (2007). Coordinated school health programs and academic achievement: A systematic review of the literature. Journal of School Health, 77(9), 589-600.

Nijmeijer JS, Minderaa RB, Buitelaar JK. (2008). Attention-deficit/ hyperactivity disorder and social dysfunctioning. Clin Psychol Rev;28:692-708.

Ridley S, Young D. (2002).Classification and measurement problems of outcomes after intensive care. In : Griffiths $\mathrm{RD}$, Jones C, eds. Intensive care after care Oxford : Butterworth-Heinemann, 142-5.

Richardson, G., Griffiths, A. M., Miller, V., \& Thomas, A. G. (2001). QoL in inflammatory bowel disease: a cross-cultural comparison of English and Canadian children. Journal of pediatric gastroenterology and nutrition, 32(5), 573-578.

Seid, M., Varni, J. W., Segall, D., \& Kurtin, P. S. (2004). Health-related quality of life as a predictor of pediatric healthcare costs: a two-year prospective cohort analysis. Health and quality of life outcomes, 2(1), 48.

Ware, J. E., Kosinski, M., Dewey, J. E., \& Gandek, B. (2000). SF-36 health survey: manual and interpretation guide. Quality Metric Inc.

Polanczyk, G., de Lima, M. S., Horta, B. L., Biederman, J., \& Rohde, L. A. (2007). The worldwide prevalence of ADHD: A systematic review and metaregression analysis. American Journal of Psychiatry, 164, 942-948.

Riley, A. W. (2006). Factors related to health-related QoL (HRQoL) among children with ADHD in europe at entry into treatment. European Child \& Adolescent Psychiatry, 15, I38-45. doi:http://dx.doi.org/10.1007/s00787006-1006-9.

Takahashi, k. , miyawaki, d. , suzuki, f. , mamoto, a. , matsushima, n. , tsuji, h. , horino, a. , ballas, p. A. And kiriike, n. (2007). Hyperactivity and comorbidity in Japanese children with attention-deficit/hyperactivity disorder. Psychiatry and Clinical Neurosciences, 61, 255-262. doi:10.1111/j.1440-1819.2007.01651.x

Theule, J. (2010). Parenting stress in families to QoL children with ADHD. Dissertation Doctor of Philosophy. University of Toronto.

Loonen, H. J., Derkx, B. H., \& Otley, A. R. (2001). Measuring health-related QoL of pediatric patients. Journal of pediatric gastroenterology and nutrition, 32(5), 523-526.

King, C. R., \& Hinds, P. S. (2011). QoL: From nursing and patient perspectives. Jones \& Bartlett Publishers.

Vaughan, B.S., H.J. Roberts., \& H.Needelman, (2009). Current medications for thetreatment of ADHD. Psychology in the Schools, 46(9), 846-856.

Strine TW, Lesesne CA, Okoro CA. (2006). Emotional and behavioral difficulties and impairments in everyday functioning among children with a history of attention-deficit/hyperactivity disorder. Prev Chronic Dis,3:A52.

Varni JW, Burwinkle TM. (2006).The PedsQL as a patient-reported outcome in children and adolescents with Attention-Deficit/Hyperactivity Disorder: A population-based study. Health Qual Life Outcomes,4:26.

Wehmeier, P. M., Schacht, A., \& Barkley, R. A. (2010). Social and emotional impairment in children and adolescents with ADHD and the impact on QoL. Journal of Adolescent Health, 46(3), 209-217.

Weyandt, L. L., \& DuPaul, G. (2006). ADHD in college students. Journal of Attention Disorders,10 (1), 9-19.

Wihartono, W. (2007). Faktor Risiko Attention Deficit/Hyperactivity Disorder pada murid sekolah SD di Kecamatan Banguntapan Kabupaten Bantul D.I. Yogyakarta: Artikel Penelitian. Berkala Kesehatan Klinik. 2007;VIII(2), 73-81.

Zambrano-Sánchez, E., Martínez-Cortés, J. A., Río-Carlos, Y. D., Dehesa-Moreno, M., \& Poblano, A. (2012). Low quality of life scores in school children with attention deficit-hyperactivity disorder related to anxiety. Arquivos de neuro-psiquiatria, 70(3), 180-184. 